\title{
Removal of cadmium from aqueous solutions by adsorption on granular red mud (GRM)
}

\author{
Chunlei Zhu ${ }^{a}$, Zhaokun Luan ${ }^{\mathrm{a}, *}$, Yanqiu Wang ${ }^{\mathrm{b}}$, Xingdong Shan ${ }^{\mathrm{b}}$ \\ a State Key Laboratory of Environmental Aquatic Chemistry, Research Center for Eco-environmental Sciences, The Chinese Academy of Sciences, \\ No. 18 Shuangqinglu Haidian District, Mailbox 2871, Beijing 100085, People's Republic of China \\ ${ }^{\mathrm{b}}$ School of Materials Science and Technology, China University of Geosciences, Beijing, People's Republic of China
}

Received 1 December 2006; received in revised form 14 March 2007; accepted 20 March 2007

\begin{abstract}
This study puts forward a novel method to prepare granular red mud (GRM) and evaluates its potential use to remove cadmium ions from aqueous solutions as a low-cost adsorbent. The properties of the novel adsorbent were examined and then used for cadmium adsorption experiments. Batch experiments were conducted and equilibrium isotherms at different temperatures $\left(20^{\circ} \mathrm{C}, 30^{\circ} \mathrm{C}, 40^{\circ} \mathrm{C}\right)$ have been determined and analyzed with a Freundlich model. Kinetics data at initial pH 6.0 and 3.0 were fitted with Pseudo-second-order model and external mass transfer coefficients, effective particle diffusion coefficients were subsequently calculated for cadmium-GRM system at initial pH 6.0. Column breakthrough curves were depicted and the data were analyzed with a Thomas model. The column adsorption was reversal and the regeneration operation was accomplished by pumping $0.1 \mathrm{~mol} / \mathrm{L}$ hydrochloric acid through the adsorbed column.
\end{abstract}

(C) 2007 Elsevier B.V. All rights reserved.

Keywords: Granular red mud; GRM; Cadmium; Adsorption

\section{Introduction}

Cadmium and cadmium compounds have been found to be very toxic and long-term exposure to cadmium can cause serious damage to a human enzyme issues especially kidneys and bones [1]. Cadmium have found its way into water bodies from many sources such as smelting, metal plating, coating, nickel-cadmium batteries, phosphate fertilizer, mining, pigments, stabilizers, alloy industries and sewage sludge [2]. However, cadmium is very difficult to remove because conventional methods employed for heavy metal removal such as chemical precipitation are either too expensive or unsuitable when confronted with the large discharge volume, low concentration waste water runoff [3].In this way adsorption method stand out for its effectiveness to remove cadmium even at low concentrations over a wide range of $\mathrm{pH}$ values [4]. Until now, many researches about cadmium adsorption have been conducted and the interest tends to be focused upon the use of low-cost, effective sorbents $[5,6]$.

\footnotetext{
* Corresponding author.

E-mail address: z6c61@163.com (Z. Luan).
}

As one of the low cost unconventional sorbents, red mud have been studied extensively for potential use as inexpensive heavy metal removal sorbents [7] and the red mud adsorbent has exhibited a high capability for cadmium removal after specific thermal or chemical treatment $[8,9]$.

However, nearly all the papers regarding about red mud adsorption have employed powdered red mud as the applied adsorbents for metal ions removal. Powdered red mud adsorbent, though endowed with a high specific adsorption area and other characteristics suitable for adsorption, are therefore inconvenient for commercial and industrial application. The unfavorable aspects regarding about powdered red mud adsorbents can be summarized as follows: (i) It is difficult to deal with the waste water produced during activation of red mud before application. (ii) It is hard to regenerate and recover after application. Therefore it is very needful to develop a low-cost and applicable granular adsorbent which is mainly prepared from powdered red mud after feasible but not complex processes.

Cherished in mind the willingness to prepare a kind of applicable granular red mud adsorbent, the study was initiated and the objective was to investigate the performance of the adsorbents and its characteristics. In this paper, the method for preparation of a novel kind of granular red mud adsorbent (GRM) will be 


\begin{tabular}{|c|c|}
\hline \multicolumn{2}{|c|}{ Nomenclature } \\
\hline$B$ & time constant \\
\hline$C_{\mathrm{e}}$ & $\begin{array}{l}\text { equilibrium concentration of metal ions in final } \\
\text { solution }(\mathrm{mg} / \mathrm{L})\end{array}$ \\
\hline$C_{\mathrm{S}}$ & surface concentration of cadmium(II) (mg/L) \\
\hline$C_{t}$ & $\begin{array}{l}\text { liquid phase concentration of metal ions at } t \\
(\mathrm{mg} / \mathrm{L})\end{array}$ \\
\hline$C_{0}$ & the initial metal ions concentration $(\mathrm{mg} / \mathrm{L})$ \\
\hline$d_{\mathrm{p}}$ & mean particle diameter $(\mathrm{mm})$ \\
\hline$D_{\text {eff }}$ & effective intraparticle diffusion coefficient $\left(\mathrm{m}^{2} / \mathrm{s}\right)$ \\
\hline$E_{\mathrm{R}}$ & column removal efficiency (\%) \\
\hline$k_{\mathrm{f}}$ & external mass transfer coefficient $(\mathrm{m} / \mathrm{s})$ \\
\hline$k_{\mathrm{TH}}$ & Thomas rate constant $\left(\mathrm{mL} \mathrm{min}^{-1} \mathrm{mg}^{-1}\right)$ \\
\hline$k_{2}$ & $\begin{array}{l}\text { pseudo-second-order kinetics constant } \\
\left(\left(\mathrm{g} \mathrm{mg}^{-1}\right) \mathrm{min}^{-1}\right)\end{array}$ \\
\hline$m_{\mathrm{cs}}$ & $\begin{array}{l}\text { mass of adsorbent for a given fixed-bed column } \\
(\mathrm{g})\end{array}$ \\
\hline$m_{\mathrm{s}}$ & adsorbent mass concentration in the solution $(\mathrm{g} / \mathrm{L})$ \\
\hline$M_{\mathrm{A}}$ & $\begin{array}{l}\text { masses of cadmium adsorbed that cannot be des- } \\
\text { orbed the last cycles (mg) }\end{array}$ \\
\hline$M_{\mathrm{D}}$ & $\begin{array}{l}\text { desorption masses eluted by desorption solution } \\
(\mathrm{mg})\end{array}$ \\
\hline$q_{\mathrm{ac}}$ & $\begin{array}{l}\text { the amount of cadmium retained by GRM packed } \\
\text { column per adsorbent }(\mathrm{mg} / \mathrm{g})\end{array}$ \\
\hline & batch adsorption capacity (mg/g) \\
\hline$q_{\mathrm{acmax}}^{\mathrm{e}}$ & $\begin{array}{l}\text { experimental maximum adsorption amount per } \\
\text { adsorbent (when saturated) (mg/g) }\end{array}$ \\
\hline$q_{\mathrm{acmax}}^{t}$ & $\begin{array}{l}\text { theoretical maximum adsorption amount per } \\
\text { adsorbent }(\mathrm{mg} / \mathrm{g})\end{array}$ \\
\hline$q_{t}$ & $\begin{array}{l}\text { amount of metal adsorbed per unit mass of adsor- } \\
\text { bent at time } t(\mathrm{mg} / \mathrm{g})\end{array}$ \\
\hline$Q$ & feed solution flow rate ( $\mathrm{mL} / \mathrm{min})$ \\
\hline$t$ & time $(\min$ or $\mathrm{h})$ \\
\hline$V$ & volume of metal ions solution (mL) \\
\hline & effluent volume (mL) \\
\hline \multicolumn{2}{|c|}{ Greek symbol } \\
\hline & bulk density $(\mathrm{g} / \mathrm{mL})$ \\
\hline
\end{tabular}

introduced without reservation, and the characteristics will be presented as well. Then the GRM will be used to remove the cadmium(II) ions from aqueous solution during batch and column adsorption tests, whereof the adsorption isotherm, kinetics and other related studies will be conducted.

\section{Experimental}

\subsection{Preparation of adsorbent}

Utilized as the principal raw materials used for granulation, red mud and fly ashes are all supplied by the Shandong Aluminum Cop. Ltd., China. The preparation procedures are depicted as Fig. 1.

\subsection{Chemicals and reagents}

All of the chemicals and reagents were at least of analytical grade and used without further purifications. The metal ion stock solutions with a concentration of $1000 \mathrm{mg} / \mathrm{L}$ were prepared from their corresponding nitrate salts. The metal ion solutions were subsequently diluted with deionized water to obtain desired concentration ranging from 5 to $400 \mathrm{mg} / \mathrm{L}$. All the tested plastic bottles and glasswares were presoaked in a $20 \% \mathrm{HNO}_{3}$ solution for 3 days, rinsed with de-ionized water and oven-dried before each experiments.

\subsection{Batch adsorption studies}

Batch studies were designed systematically to obtain a series of experimental data for the controlled strength and $\mathrm{pH} .0 .20 \mathrm{~g}$ of granular red mud adsorbent were weighted and put into $100 \mathrm{~mL}$ sealed plastic bottle with a $3 \mathrm{~cm}$ internal diameter, into which $50 \mathrm{~mL}$ adsorbate solutions were added first. The sample bottles were then fixed in a temperature-controlled shaker for 8-24 h. Except for the adsorption equilibrium isotherms experiments, other adsorption experiments were all run at $20 \pm 0.5^{\circ} \mathrm{C}$. Blank solutions were also run at the same $\mathrm{pH}$ (3.0 or 6.0) simultaneously to minimize the errors caused by the background. Until otherwise noted, the support electrolyte was $0.01 \mathrm{~mol} / \mathrm{L}$ $\mathrm{NaNO}_{3}$. To ensure a sufficient interaction between $\mathrm{Cd}$ ions and granular red mud adsorbent, the agitation speed of the shaker was adjusted to $450 \mathrm{rpm}$ for all the batch experiments. After agitation, the adsorbate solution was filtered directly through a $0.45 \mu \mathrm{m}$ cellulose acetate membrane without centrifugation. The filtrate was then analyzed by an atomic absorption spectrophotometer (Shimadzu AA 6300) that is equipped with both flare combustion and graphite furnace spectrophotometer, which were employed respectively according to different concentrations. The $\mathrm{pH}$ values for the adsorptive systems were accurately controlled by adding $\mathrm{HCl}$ or $1 \mathrm{~mol} / \mathrm{L} \mathrm{NaOH}$ with a $10 \mu \mathrm{L}$ microinjector when close to the desired $\mathrm{pH}$ and the $\mathrm{pH}$ values were all measured by a $\mathrm{pH}$ meter (ORION, 710A) simultaneously. All the experiments were replicated in triplicate to ensure accuracy.

To fully study the adsorption characteristics of GRM adsorbent and determine the maximum adsorption capacity under experimental condition, the cadmium adsorption equilibrium isotherms were run for 13 different initial $\mathrm{Cd}(\mathrm{II})$ concentrations $(5 \mathrm{mg} / \mathrm{L}, 10 \mathrm{mg} / \mathrm{L}, 20 \mathrm{mg} / \mathrm{L}, 30 \mathrm{mg} / \mathrm{L}, 40 \mathrm{mg} / \mathrm{L}, 50 \mathrm{mg} / \mathrm{L}$, $100 \mathrm{mg} / \mathrm{L}, 150 \mathrm{mg} / \mathrm{L}, 200 \mathrm{mg} / \mathrm{L}, 250 \mathrm{mg} / \mathrm{L}, 300 \mathrm{mg} / \mathrm{L}, 350 \mathrm{mg} / \mathrm{L}$ and $400 \mathrm{mg} / \mathrm{L})$ added as $\mathrm{Cd}\left(\mathrm{NO}_{3}\right)_{2}$ at $20^{\circ} \mathrm{C}, 30^{\circ} \mathrm{C}$ and $40^{\circ} \mathrm{C}$, respectively. The $\mathrm{pH}$ for this $\mathrm{GRM}$-adsorbate systems were all controlled as $\mathrm{pH}$ 6.0.

Batch kinetic experiments were conducted for 3 different initial Cd(II) concentrations (50 mg/L, $100 \mathrm{mg} / \mathrm{L}$ and $200 \mathrm{mg} / \mathrm{L}$ ) at initial pH 3.0 and initial pH 6.0.

The adsorption capacity of $\mathrm{Cd}(\mathrm{II})$ ions by granular red mud were calculated by the following mass balance equation:

$q_{\mathrm{e}}=\frac{C_{0}-C_{\mathrm{e}}}{m_{\mathrm{s}}} \times V$ 


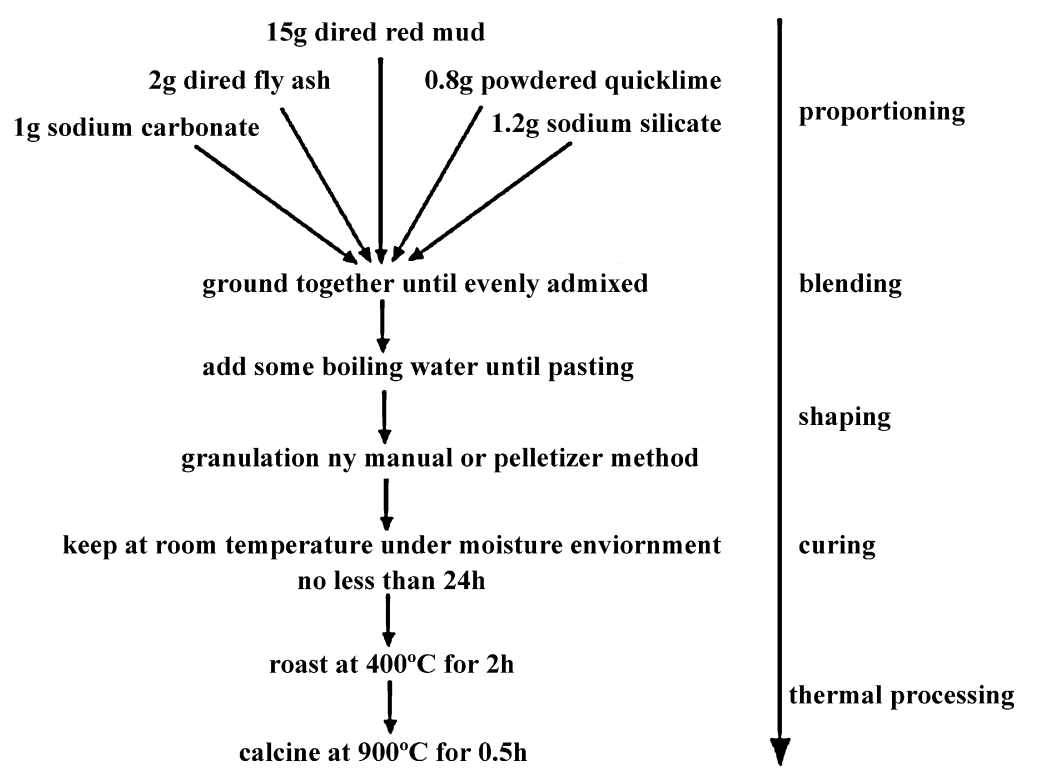

Fig. 1. Preparation procedure of granular red mud (GRM) adsorbent (the amount for each component can also be quantified as ratio to other components).

\subsection{Column adsorption studies}

The fixed-bed column system mainly consisted of a small magnetic-pump and a vertical plastic column with an inner diameter $4.0 \mathrm{~cm}$ and a height of $8.0 \mathrm{~cm}$. Granular red mud adsorbents were packed into the column as fixed bed with a predetermined adsorbent mass of $71 \mathrm{~g}$. A fixed mass flux of initial cadmium influent of $25 \mathrm{mg} / \mathrm{min}$ were driven to move through two identical columns respectively with a same fixed-bed height. The fixed mass flux of cadmium inlet of $25 \mathrm{mg} / \mathrm{min}$ for the two identical columns were ascertained by varying flow rates (hydraulic load) and initial cadmium concentrations (inlet concentration) as " $5 \mathrm{~mL} / \mathrm{min}, 5 \mathrm{mg} / \mathrm{L}$ "(column 1) and " $2.5 \mathrm{~mL} / \mathrm{min}, 10 \mathrm{mg} / \mathrm{L}$ " (column 2), respectively. The two column systems were run using initial cadmium solutions with an initial $\mathrm{pH} 6.0$ and cadmium concentration below $10 \mathrm{mg} / \mathrm{L}$, as in many engineering cases the cadmium-polluted waters are in low concentrations. The treated effluents were sampled at intervals and sent to analyze by AAS. The amount of $\mathrm{Cd}(\mathrm{II})$ that is adsorbed by the GRM packed fixed-bed was determined through a mass balance in the column using the breakthrough data as Eq. (2), and the column removal efficiency $E_{\mathrm{R}}$ were calculated by the following equation:

$$
\begin{aligned}
& q_{\mathrm{ac}}=\frac{C_{0} Q}{1000 m_{\mathrm{cs}}} \int_{0}^{t}\left(1-\frac{C_{t}}{C_{0}}\right) \mathrm{d} t \\
& E_{\mathrm{R}}(\%)=\frac{q_{\mathrm{ac}} \cdot m_{\mathrm{cs}}}{C_{0} \cdot Q \cdot t} \times 100
\end{aligned}
$$

\subsection{Column regeneration studies}

To retrieve the GRM adsorbents and reuse saturated column, regeneration experiments were conducted by pumping proper desorption solvents through exhausted column. In the present study, the column previously run under " $5 \mathrm{~mL} / \mathrm{min}, 5 \mathrm{mg} / \mathrm{L}$ " was chosen in desorption experiments on account of representativeness. The regenerated column was then used for the next cycle of column adsorption. All together four cycles of regeneration experiments were conducted until the retained cadmium amount by GRM column are more than the amount recovered by desorption solution. After each cycle of regeneration, the column was washed by de-ionized water. Taken into consideration the accumulative masses amount by former adsorption cycles, the desorption efficiency $E_{\mathrm{D}}$ is calculated as (for one cycle) Eq. (4):

$E_{\mathrm{D}}(\%)=\frac{M_{\mathrm{D}}}{\left(q_{\mathrm{ac}} \cdot m_{\mathrm{cs}}+M_{\mathrm{A}}\right)} \times 100$

where $q_{\mathrm{ac}}, m_{\mathrm{cs}}$ is defined as the same as above; $M_{\mathrm{D}}$ the desorption masses eluted by desorption solution; $M_{\mathrm{A}}$ is the masses of retained cadmium adsorbed that cannot be desorbed.

\section{Results and discussion}

\subsection{Characterization of adsorbent}

After preparation by the method above, the physical and chemical properties of GRM were examined and the results were listed in Table 1.

The chemical composition of the granular red mud adsorbent were analyzed through conventional method by the chemical analysis of aluminosilicates [10]. The textural characteristics

Table 1

\begin{tabular}{|c|c|c|c|}
\hline \multicolumn{2}{|c|}{ Chemical compositions } & \multicolumn{2}{|l|}{ Physical properties } \\
\hline Constituents & Limits (wt\%) & Items & Limits \\
\hline $\mathrm{SiO}_{2}$ & 33.44 & Specific surface area & $15.28 \mathrm{~m}^{2} \mathrm{~g}^{-1}$ \\
\hline $\mathrm{Al}_{2} \mathrm{O}_{3}$ & 18.56 & Bulk density (dry) & $0.68 \mathrm{~g} \mathrm{~cm}^{-3}$ \\
\hline $\mathrm{CaO}$ & 11.54 & Total pore volume & $0.125 \mathrm{~cm}^{3} \mathrm{~g}^{-1}$ \\
\hline $\mathrm{MgO}$ & 1.85 & Pore size distribution & $2.5-18.5 \mathrm{~nm}$ \\
\hline $\mathrm{TiO}_{2}$ & 6.88 & $\mathrm{pH}_{\mathrm{zpc}}$ & 4.5 \\
\hline $\mathrm{Na}_{2} \mathrm{O}$ & 5.24 & Average particle radii & $1.5 \pm 0.25 \mathrm{~mm}$ \\
\hline $\mathrm{Fe}_{2} \mathrm{O}_{3}$ & 16.02 & Particle color & Brown yellow \\
\hline
\end{tabular}

Physical and chemical properties of GRM 
(a)

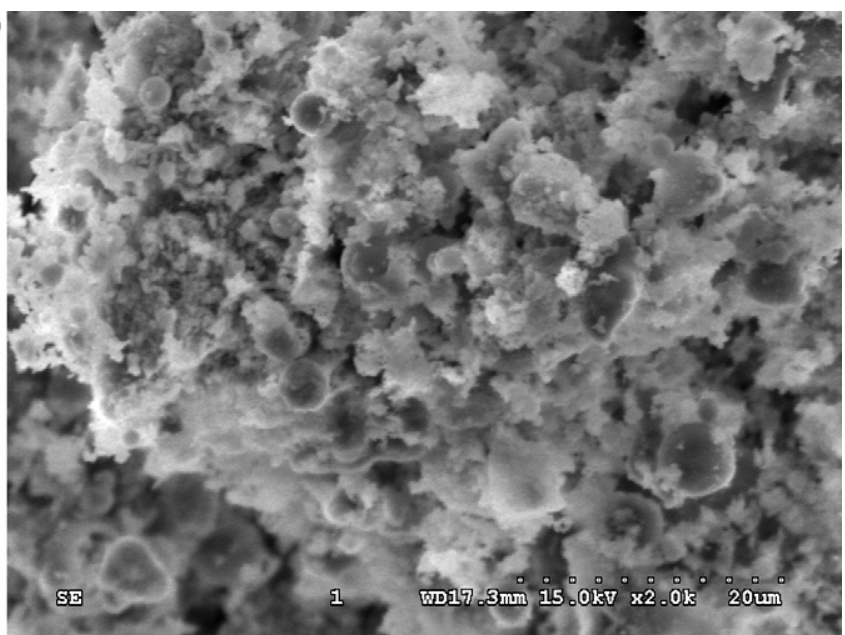

(b)

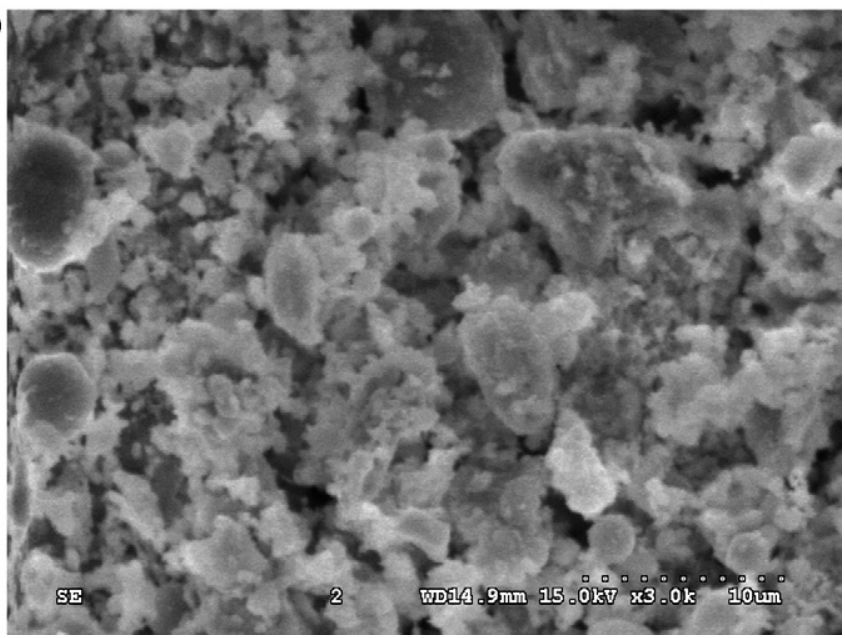

Fig. 2. SEM micrograph of GRM at different magnification: (a) $2000 \times$ and (b) $3000 \times$.

like specific surface area, total pore volume and pore size distribution were measured by applying the BET method on a BET surface-area analyser (Micromeritics ASAP 2000). $\mathrm{pH}_{\mathrm{zpc}}$ ( $\mathrm{pH}$ of zero point of charge) was determined according to the alkalinetitration procedures [11]. As seen from Fig. 2, scanning electron microscopy (HITACHI S-3000N) examination shows a homogeneous surface of GRM. The whisker crystalline structures and fine fly ash particles can also be observed from Fig. 2, which all indicate a favorable texture for metal ions adsorption on GRM surface. The XRD (Rikaku D/max-RB $\mathrm{Cu} \mathrm{K} \alpha$ ) analysis shows that GRM are mainly composed of quartz, calcium titanium silicates, sodium aluminosilicates, iron oxides (hematite), and hydroxides and other amorphous minerals, as reported by former researchers as the active components of metal ions adsorption [7-9].

\subsection{Batch adsorption studies}

The adsorption of cadmium by GRM was conducted in different initial cadmium concentration ranging from $5 \mathrm{mg} / \mathrm{L}$ to $400 \mathrm{mg} / \mathrm{L}$ at a fixed $\mathrm{pH}$ 6.0. Adsorption equilibrium data were subsequently collected and correlated at three different tem-

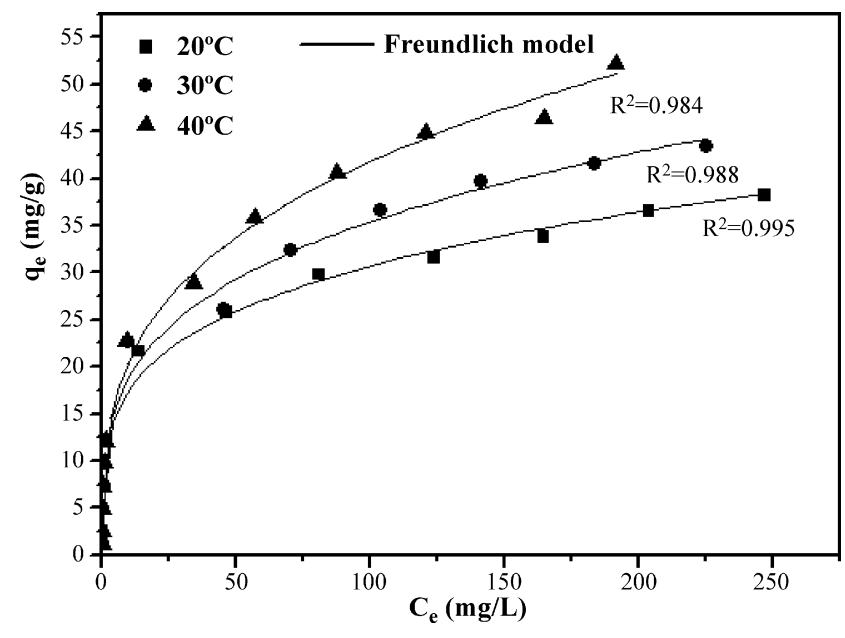

Fig. 3. Batch adsorption isotherms of cadmium at different temperatures.

peratures $\left(20^{\circ} \mathrm{C}, 30^{\circ} \mathrm{C}\right.$ and $\left.40^{\circ} \mathrm{C}\right)$. It is found that the data are regular and can be favorably modeled by the Freundlich isotherms (Fig. 3). The isotherm parameters were then obtained and listed in Table 3. From the results, it can be seen that the correlation coefficients are near 1 and the values $1 / n$ are all far below 1 , which indicate a high affinity of cadmium ions by GRM. As seen also from Fig. 3 that the equilibrium adsorption capacity of cadmium ions by GRM increased with the increasing initial concentration of cadmium up to $400 \mathrm{mg} / \mathrm{L}$, and also increased with the change of temperature from $20^{\circ} \mathrm{C}$ to $40^{\circ} \mathrm{C}$. As a result, granular red mud exhibits itself a high capability to adsorb Cd ions from aqueous solutions in that a nearly complete removal is accomplished when the adsorbate concentrations are below $50 \mathrm{mg} / \mathrm{L}$. The maximum adsorption capacities for GRM observed in the experiments were determined as $38.2 \mathrm{mg} / \mathrm{g}$ at $20{ }^{\circ} \mathrm{C}, 43.4 \mathrm{mg} / \mathrm{g}$ at $30^{\circ} \mathrm{C}$ and $52.1 \mathrm{mg} / \mathrm{g}$ at $40{ }^{\circ} \mathrm{C}$. The comparison of maximum adsorption capacities with other low-cost adsorbents are listed in Table 2, which indicate that the GRM adsorbent have a medium cadmium adsorption capacity among the adsorbents (mainly powdered adsorbents).

The adsorptive behavior of GRM with respect to temperature can be further explained by the thermodynamic parameters as for the changes of standard free energy $\left(\Delta G^{\circ}\right)$, enthalpy $\left(\Delta H^{\circ}\right)$ and entropy $\left(\Delta S^{\circ}\right)$, which were determined by using the following equations:

$K_{\mathrm{c}}=\frac{C_{\mathrm{A}}}{C_{\mathrm{e}}}$

$\Delta G^{\circ}=-R T \ln K_{\mathrm{c}}$

Table 2

Adsorption capacities for different adsorbents

\begin{tabular}{lcl}
\hline Adsorbent & Adsorption capacity $(\mathrm{mg} / \mathrm{g})$ & Reference \\
\hline Granular activated carbon & 3.4 & {$[12]$} \\
Modified corncobs & 9.0 & {$[13]$} \\
Pine bark & 28.0 & {$[14]$} \\
Peat & 50 & {$[6]$} \\
Fly ash & 198.2 & {$[15]$} \\
Powdered red mud & 66.8 & {$[15]$} \\
\hline
\end{tabular}


Table 3

Freundlich model and thermodynamic parameters for adsorption of $\mathrm{Cd}^{2+}$ on GRM

\begin{tabular}{lcccc}
\hline Temperature $\left({ }^{\circ} \mathrm{C}\right)$ & $K_{\mathrm{F}}(\mathrm{mg} / \mathrm{g})$ & $1 / n$ & $-\Delta G^{\circ}(\mathrm{kJ} / \mathrm{mol})$ & $\Delta H^{\circ}(\mathrm{kJ} / \mathrm{mol})$ \\
\hline 20 & 9.86 & 0.25 & 4.546 & $\Delta S^{\circ}(\mathrm{J} / \mathrm{mol} \mathrm{K})$ \\
30 & 10.02 & 0.27 & 5.620 & 15.822 \\
40 & 10.10 & 0.31 & 5.933 & 69.653 \\
\hline
\end{tabular}

Note: Freundlich model: $q_{\mathrm{e}}=K_{\mathrm{F}}\left(C_{\mathrm{e}}\right)^{1 / n}$; where $K_{\mathrm{F}}$ in $\mathrm{mg} / \mathrm{g} ; q_{\mathrm{e}}$ in $\mathrm{mg} / \mathrm{g} ; C_{\mathrm{e}}$ in $\mathrm{mg} / \mathrm{mL}$.

$\ln K_{\mathrm{c}}=\frac{\Delta S^{\circ}}{R}-\frac{\Delta H^{\circ}}{R T}$

where $K_{\mathrm{c}}$ is the equilibrium constant, $C_{\mathrm{e}}$ the equilibrium concentration in solution $(\mathrm{mg} / \mathrm{L})$ and $C_{\mathrm{A}}$ is the solid-phase concentration at equilibrium $(\mathrm{mg} / \mathrm{L})$.

$\Delta H^{\circ}$ and $\Delta S^{\circ}$ were obtained from the slope and intercept of the Van't Hoff plot (Fig. 4) applied by Eq. (6). The results obtained were listed in Table 3 . The negative of free energy $\Delta G^{\circ}$ shows that the adsorption on GRM is a spontaneous and feasible process. The positive value of enthalpy $\Delta H^{\circ}$ indicates the endothermic nature of cadmium adsorption and the positive entropy $\Delta S^{\circ}$ suggests the increased randomness at the solidsolution interface during the adsorption of cadmium on GRM.

\subsection{Batch adsorption kinetics}

The kinetics of adsorption in GRM-cadmium system reflects the rate of cadmium adsorption on GRM and the time required to reach equilibrium, which is crucial for the understanding of adsorption process and adsorbent performance. The experimental adsorption kinetics data were analyzed by applying the pseudo-second-order kinetics model, which is expressed as Eq. (8a):

$\frac{\mathrm{d} q_{t}}{\mathrm{~d} t}=k_{2}\left(q_{\mathrm{e}}-q_{t}\right)^{2}$

linearized form of equation is $(8 b)$ :

$\frac{t}{q_{t}}=\frac{1}{k_{2} q_{\mathrm{e}}^{2}}+\frac{1}{q_{\mathrm{e}}} t$

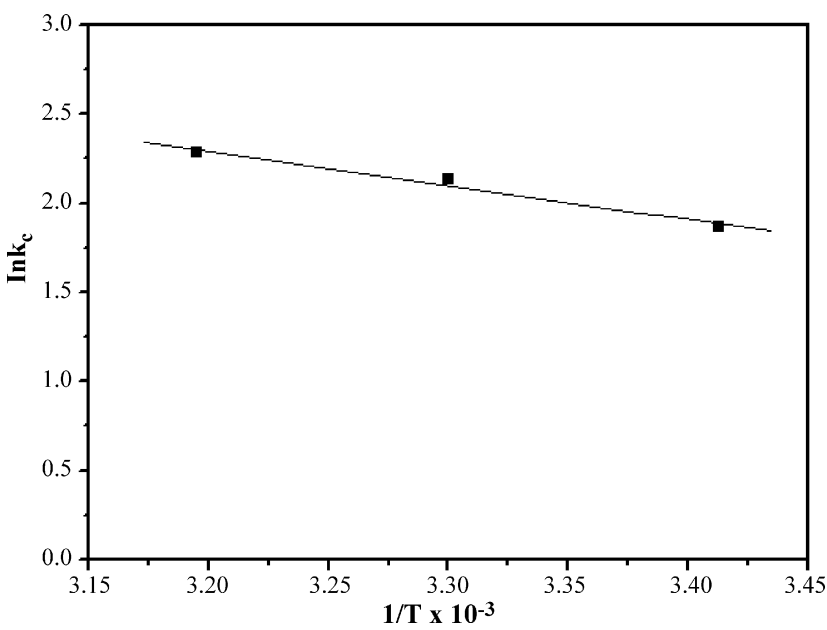

Fig. 4. Van't Hoff plot for the adsorption of cadmium ions. Conditions: GRM dosage $4 \mathrm{~g} / \mathrm{L}, \mathrm{pH} 6.0$.

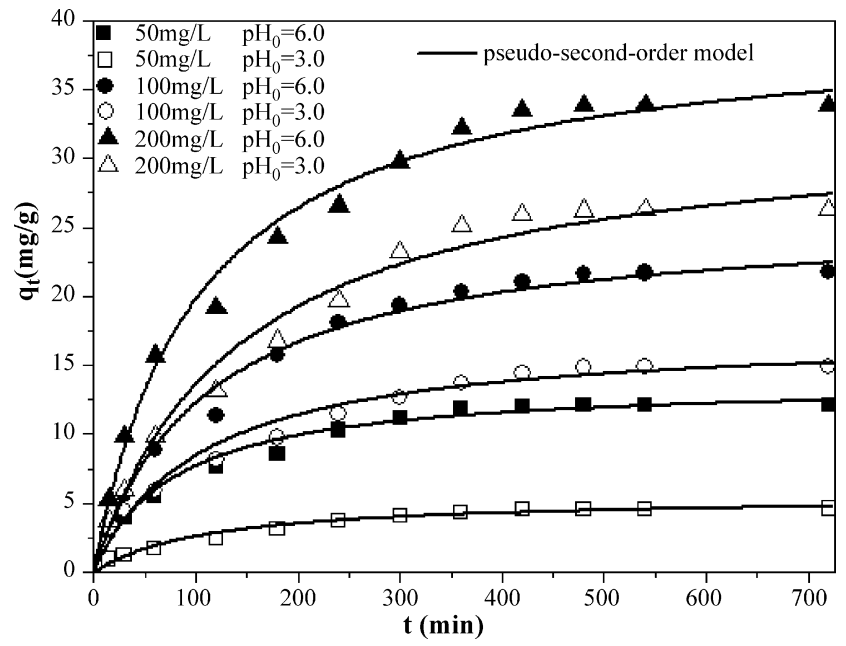

Fig. 5. Pseudo-second-order kinetics plots for cadmium adsorption at $\mathrm{pH} 3.0$ and $\mathrm{pH} 6.0$.

where $k_{2}(\mathrm{~g} /(\mathrm{mg} \min ))$ is the pseudo-second-order kinetics constant, $q_{t}$ the amount of metal adsorbed per unit mass of adsorbent at $t$ (time) and $q_{\mathrm{e}}(\mathrm{mg} / \mathrm{g})$ is the amount of metal adsorbed per unit mass of adsorbent at equilibrium.

The statistical data have shown a fair goodness of correlation for pseudo-second-order kinetics (Fig. 5), which were reported previously for heavy metal adsorption by other low-cost adsorbents, such as peat and zeolite for the indication for a potential application in column water treatment $[6,16]$. After the application of the pseudo-second-order kinetics model, the results were listed in Table 4 . The kinetics results were also reflected by the plot of $q_{t}$ versus time curves in Fig. 5. As shown from the plot, the major percent of cadmium adsorption process was completed in $8 \mathrm{~h}$ as for the different initial concentrations of GRM-cadmium system, which indicate itself a relatively moderate rate to reach adsorption equilibrium [6]. Fig. 5 also shows that the initial $\mathrm{pH}$ has an obvious influence upon the cadmium adsorption rate and a higher initial $\mathrm{pH}$ is favorable for cadmium

Table 4

Pseudo-second-order kinetics constants and related regression coefficients

\begin{tabular}{lcll}
\hline $\mathrm{pH}$ & $\mathrm{Cd}(\mathrm{mg} / \mathrm{L})$ & $k_{2}(\mathrm{~g} /(\mathrm{mg} \min ))$ & $R^{2}$ \\
\hline 3.0 & 50 & $1.644 \times 10^{-3}$ & 0.988 \\
& 100 & $0.548 \times 10^{-3}$ & 0.982 \\
& 200 & $0.219 \times 10^{-3}$ & 0.980 \\
& & & \\
6.0 & 50 & $0.923 \times 10^{-3}$ & 0.994 \\
& 100 & $0.352 \times 10^{-3}$ & 0.992 \\
& 200 & $0.25 \times 10^{-3}$ & 0.986 \\
\hline
\end{tabular}




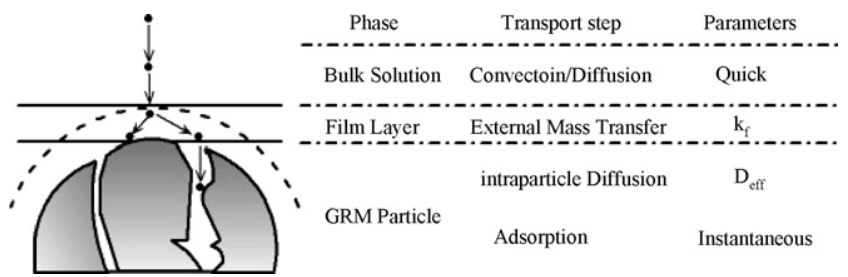

Fig. 6. Schematic representation of mass transfer process in GRM-adsorbate system.

adsorption by GRM. After adsorption, the measured final $\mathrm{pH}$ values for initial pH 3.0 solution ranged between 3.8 and 4.6, and for $\mathrm{pH} 6.0$ ranging between 6.8 and 7.3, which reveals that the prepared GRM particle can effectively prevent the addition of alkalinity usually caused by the hydroxyl ions released from red mud constituent even under acidic environment.

\subsection{Batch mass transfer studies}

To further study the mass transfer mechanism involved in cadmium adsorption by GRM, it is essential to identify the governing step during the GRM-cadmium batch adsorption system, the pore diffusion model was adopted to study the mass transfer process for GRM-cadmium batch adsorption system at $\mathrm{pH}$ 6.0, as described by the well-known schematic representation of Fig. 6. It can be seen that for a traditional solid-liquid adsorption process, the mass transfer process can be divided into four steps which are usually characterized as follows $[17,24]$ :

(1) Random convection or diffusion in bulk solution.

(2) External mass transfer from solution to the exterior surface of GRM particle through film layer.

(3) Intraparticle diffusion within GRM particle.

(4) Very quick (instantaneous) adsorption on the exterior surface or interior pore surface of the adsorbent.

Of the four mass transfer steps, the random convection step or diffusion in bulk solution step is quick due to the high agitating or shaking speed while the adsorption of cadmium on the adsorbent is very rapid as for equilibrium reaction. Thereby, the mass transfer process are mainly governed by the intraparticle or film diffusion mechanisms. The judgment of rate-controlling step can be accomplished through the analysis of the external mass transfer coefficients $k_{\mathrm{f}}$ and effective particle diffusion coefficients $D_{\text {eff. }}$, which are in fact derived from the further interpretation of kinetics data acquired from experimental results.

External mass transfer coefficient $k_{\mathrm{f}}$ for GRM-cadmium system at initial pH 6.0 was calculated through Eq. (9b) derived from the mass balance of solution-adsorbent system as differential equation (9a) when $t \rightarrow 0, C_{t} \rightarrow C_{0}$, and $C_{\mathrm{S}}, q_{t} \rightarrow 0$ $[18,19]$. After acquisition of slope rate for the plot of $C_{t}$ versus $t$ when $t=0$, the external mass transfer coefficient $k_{\mathrm{f}}$ can be determined. For different initial cadmium concentration of $50 \mathrm{mg} / \mathrm{L}$, $100 \mathrm{mg} / \mathrm{L}$ and $200 \mathrm{mg} / \mathrm{L}, k_{\mathrm{f}}$ was calculated as $2.252 \times 10^{-5} \mathrm{~m} / \mathrm{s}$, $1.360 \times 10^{-5} \mathrm{~m} / \mathrm{s}$ and $1.002 \times 10^{-5} \mathrm{~m} / \mathrm{s}$. The calculated coefficients have shown a non-proportionality with the change of initial adsorbate concentration, which indicates that the exter- nal mass transfer process of GRM-cadmium system is not the rate-controlling step $[20,21]$ :

$\frac{\mathrm{d} C_{t}}{\mathrm{~d} t}=-k_{\mathrm{f}} \frac{6 m_{\mathrm{s}}}{d_{\mathrm{p}} \rho_{\mathrm{b}}}\left(C_{t}-C_{\mathrm{s}}\right)$

$k_{\mathrm{f}}=-\frac{d_{\mathrm{p}} \rho_{\mathrm{b}}}{6 m_{\mathrm{s}} C_{0}}\left(\frac{\mathrm{d} C_{t}}{\mathrm{~d} t}\right)_{t=0}$

The effective particle diffusion coefficients can also be obtained through the quantitative treatment of the adsorption dynamics data that is in accordance with the procedure given by Reichenberg [22] and Helfferich [23], as expressed by the following equation:

$$
\begin{aligned}
F & =\frac{q_{t}}{q_{\mathrm{e}}}=1-\frac{6}{\pi^{2}} \sum_{n=1}^{\infty} \frac{1}{n^{2}} \exp \left(-\frac{n^{2} \pi^{2}}{r_{0}^{2}} D_{\text {eff }} t\right) \\
& =1-\frac{6}{\pi^{2}} \sum_{n=1}^{\infty} \frac{1}{n^{2}} \exp \left(-n^{2} B t\right)
\end{aligned}
$$

where $B$ is time constant $\left(B=\left(\pi^{2} / r_{0}^{2}\right) D_{\text {eff }} t\right), F$ the fractional attainment of equilibrium at time $t\left(F=q_{t} / q_{\mathrm{e}}\right), D_{\text {eff }}$ the effective diffusion coefficient of cadmium ions in the adsorbent (GRM) phase and $r_{0}$ is the radius of spherical adsorbent particles. The term $\mathrm{n}$ is an integer that defines the infinite series solution.

$B t$ values (the product of multiplying $B$ by time $t$ ) at $\mathrm{pH} 6.0$ were obtained for each observed value of $F$ from Reichenberg's table. The linearity test of $B t$ versus time plots was employed to distinguish between adsorption controlled by external versus intraparticle diffusion. If a $B t$ versus time plot ( $\operatorname{slope}=B$ ) is linear and passes through the origin, then the adsorption rate is governed by diffusion in the particle. Otherwise, it is governed by film diffusion considered as external mass transfer. The results are listed in Table 5.

The $B t$ versus time plots for $\mathrm{Cd}^{2+}$ adsorption at initial $\mathrm{pH} 6.0$ were depicted in Fig. 7a. The plots are all linear $\left(R^{2}>0.977\right)$ and pass through the origin, which indicate that the mass transfer process in GRM-cadmium system are intraparticle-diffusioncontrolled at pH $6.0[24,25]$.

Further verification of the above deductions was conducted by Mckay's graph. The typical Mckay's plots of $\log (1-F)$ versus time in consistence to Bt versus time plot were also depicted in Fig. 7b, wherein straight lines (except for the final value near equilibrium) can be observed for the tested concentrations which further supports the fact that intraparticle transport of cadmium is more prominent in GRM-cadmium system [26].

Table 5

External mass transfer coefficients and effective particle diffusion coefficients for cadmium adsorption by GRM

\begin{tabular}{llll}
\hline $\mathrm{pH}$ & $\mathrm{Cd}^{2+}(\mathrm{mg} / \mathrm{L})$ & $k_{\mathrm{f}}\left(\times 10^{5} \mathrm{~m} / \mathrm{s}\right)$ & $D_{\text {eff }}\left(\times 10^{13} \mathrm{~m}^{2} / \mathrm{s}\right)$ \\
\hline 6.0 & 50 & 2.252 & 1.425 \\
& 100 & 1.360 & 1.132 \\
& 200 & 1.002 & 1.062 \\
\hline
\end{tabular}




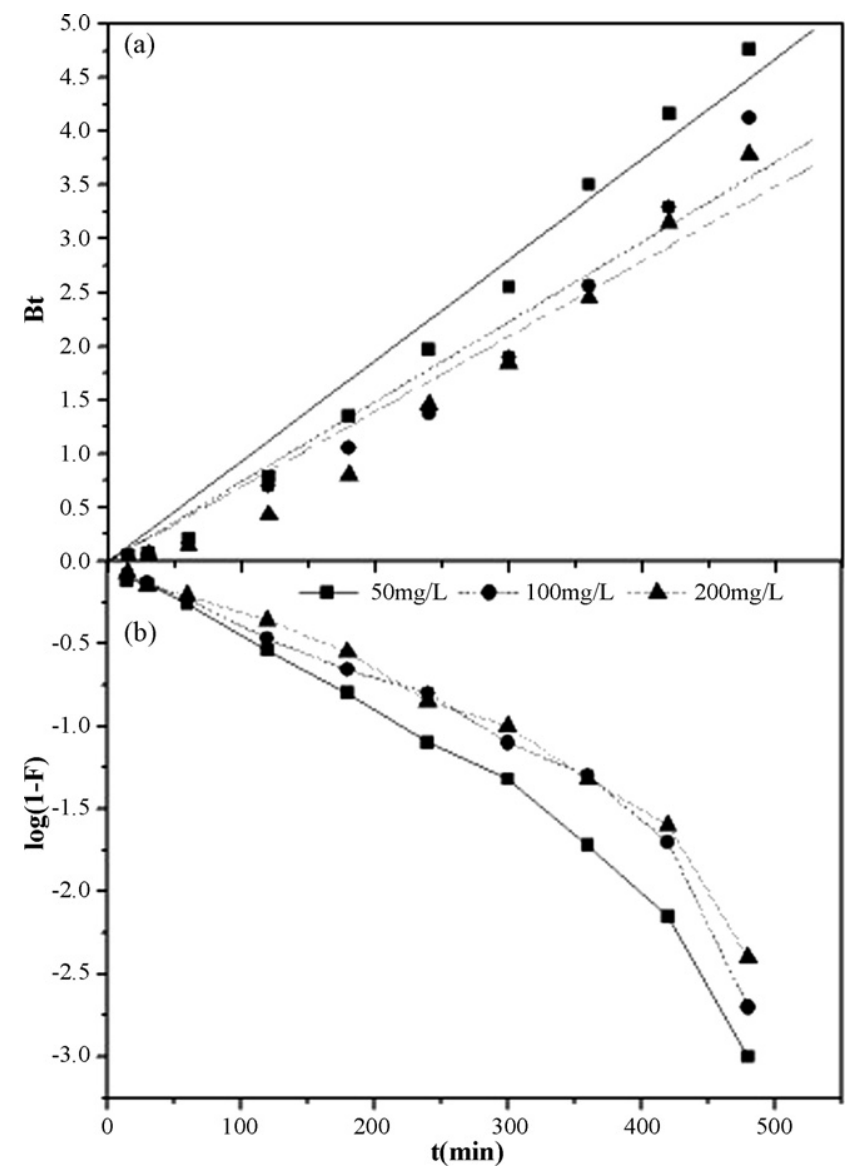

Fig. 7. (a) Time vs. Bt plot for different initial concentrations of cadmium at $\mathrm{pH}$ 6.0. (b) Time vs. $\log (1-F)$ plot for different initial concentrations of cadmium at $\mathrm{pH}$ 6.0.

\subsection{Continuous column studies}

To study the column adsorptive performance of GRM under varied condition at a laboratory scale, two identical columns packed with a same mass of adsorbents were set up to study the adsorption of cadmium by continuous fixed-bed absorbers. Purpose of this design is to judge whether "high inlet flow rate, low concentration" or "high inlet concentration, low flow rate" with a same mass flux inlet is more favorable for the processing of equal mass flux inlet of cadmium.

The breakthrough curves of the identical columns were plotted in Fig. 8a. The column adsorption capacity, removal efficiency and the breakthrough time were subsequently determined and listed in Table 6. As seen from the calculated parameters, the second column with "high inlet concentration, low flow rate"

Table 6

Column adsorption parameters for intercompared columns with a same mass flux inlet

\begin{tabular}{|c|c|c|c|c|c|c|}
\hline \multirow{2}{*}{$\begin{array}{l}\text { Breakthrough } \\
\text { point }\end{array}$} & \multicolumn{2}{|c|}{$q_{\mathrm{ac}}(\mathrm{mg} / \mathrm{g})$} & \multicolumn{2}{|c|}{$E_{\mathrm{R}}(\%)$} & \multicolumn{2}{|c|}{$t(\mathrm{~h})$} \\
\hline & 1 & 2 & 1 & 2 & 1 & 2 \\
\hline$C_{t} / C_{0}=0.1$ & 2.48 & 2.69 & 72.6 & 68.1 & 160 & 192 \\
\hline$C_{t} / C_{0}=0.5$ & 4.47 & 5.12 & 70.0 & 73.9 & 298 & 328 \\
\hline$C_{t} / C_{0}=1.0$ & 5.92 & 6.69 & 58.2 & 59.1 & 482 & 548 \\
\hline
\end{tabular}

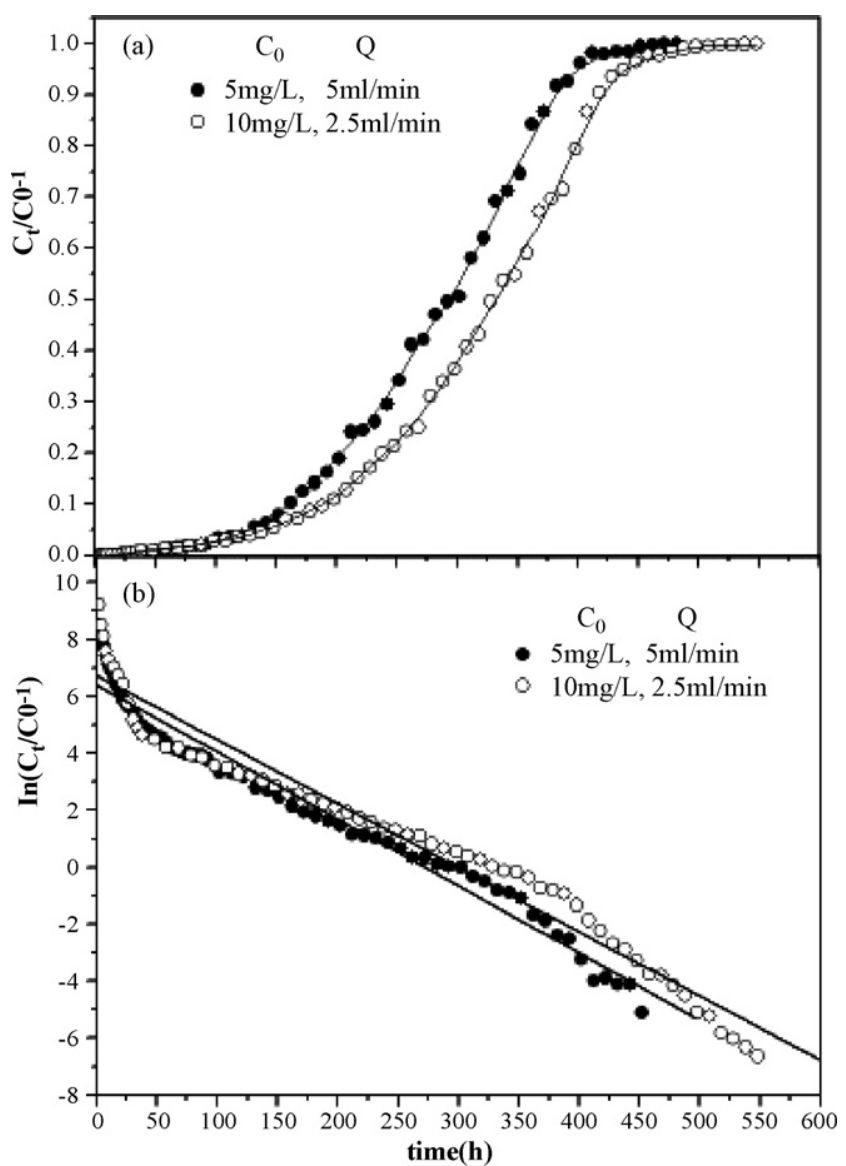

Fig. 8. (a) Breakthrough curves of adsorption of cadmium with a same mass flux inlet. (b) Linear plots of $\ln \left(C_{0} / C_{t}-1\right)$ vs. $t$ by application of Thomas model.

have exhibited a better ability to adsorb the same inlet mass flux before exhausted with larger adsorption capacity efficiency, a higher total removal and longer service time. Also concluded from the results (Table 7) is that the breakthrough capacities ( $\left.q_{\text {acmax }}\right)$ of the two columns are higher than their respective batch capacities (for $4 \mathrm{~g} / \mathrm{L}$ dose in this report) according to a same initial cadmium concentration.

Thomas model was used to further analyze the column adsorption results as to assess column adsorption kinetic parameters [27,28]. The linearized form of Thomas model is expressed as the following:

$\ln \left(\frac{C_{0}}{C_{t}}-1\right)=-k_{\mathrm{TH}} C_{0} t+k_{\mathrm{TH}} \frac{q_{\mathrm{acmax}}^{t} m_{\mathrm{s}}}{Q}$

Fig. $8 \mathrm{~b}$ shows the analytical curve after application of the above model, the two model parameters $k_{\mathrm{TH}}$ and $q_{\mathrm{acmax}}^{t}$ could then be acquired from this plot of $\ln \left[C_{0} / C_{t}-1\right]$ versus $t$. As for column 1 of " $5 \mathrm{mg} / \mathrm{L}, 5 \mathrm{~mL} / \mathrm{min}$ " and column 2 of " $10 \mathrm{mg} / \mathrm{L}$,

Table 7

Comparison of adsorption capacity between batch and column studies

\begin{tabular}{lll}
\hline Initial concentration $(\mathrm{mg} / \mathrm{L})$ & $q_{\mathrm{e}}(\mathrm{mg} / \mathrm{g})$ & $q_{\mathrm{acmax}}^{\mathrm{e}}(\mathrm{mg} / \mathrm{g})$ \\
\hline 5 & 1.25 & 5.92 \\
10 & 2.5 & 6.69
\end{tabular}


Table 8

Thomas model parameters for GRM-packed columns

\begin{tabular}{lclll}
\hline$Q(\mathrm{~mL} / \mathrm{min})$ & $C_{0}(\mathrm{mg} / \mathrm{L})$ & $\begin{array}{l}K_{\mathrm{TH}}(\times 100 \mathrm{~mL} / \\
(\mathrm{min} \mathrm{mg}))\end{array}$ & \multicolumn{2}{l}{$q_{\text {acmax }}(\mathrm{mg} / \mathrm{g})$} \\
\cline { 3 - 5 } & & & Theory & Test \\
\hline 5 & 5 & 7.84 & 5.75 & 5.92 \\
2.5 & 10 & 3.75 & 6.31 & 6.69 \\
\hline
\end{tabular}

$2.5 \mathrm{~mL} / \mathrm{min}$ ", the Thomas rate constant calculated for the two columns are listed in Table 8, which show a fine correlative agreement with the experimental data in Table 7. The successful simulation of the experimental results demonstrate the validity of applying Thomas model for the design and simulation of column adsorption.

\subsection{Column regeneration}

As an important criteria for thorough evaluation of the performance of an adsorbent, the cadmium-loaded GRM adsorbents are expected to be regenerated for certain cycles and it is also essential to develop a practical regeneration method of exhausted adsorbent for economical reasons. Though a relatively higher concentration of regenerant solution can be helpful to column desorption, the choice of proper concentration is crucial for the consideration of regenerant cost and its adverse effects upon adsorbent endurance. Devised for a traditional test, the recovery of GRM column was accomplished by eluting $0.1 \mathrm{~mol} / \mathrm{L} \mathrm{HCl}$ solution through the exhausted fixed-bed column 1 previously run under " $5 \mathrm{~mL} / \mathrm{min}, 5 \mathrm{mg} / \mathrm{L}$ ". The regeneration solution was fed to the bottom of the fixed bed by a magnetic pump with a flow rate of $50 \mathrm{~mL} / \mathrm{min}$. The four cycles of desorption curves was plotted in Fig. 9 and the desorption masses by recovery solution was calculated in the way identical to calculation of the column adsorption amounts.

As a result, the calculated column desorption parameters were listed in Table 9, which indicates that hydrochloric acid with a

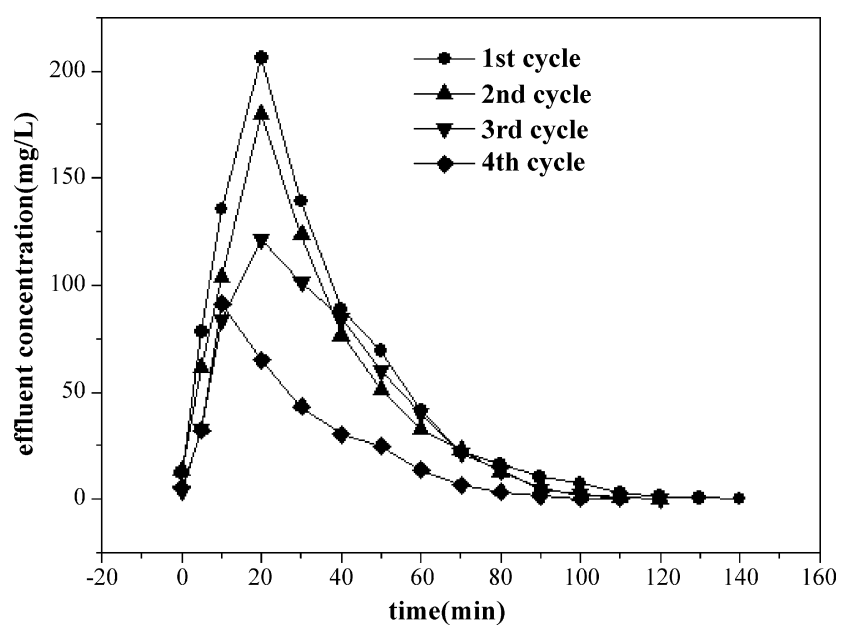

Fig. 9. Desorption curves of cadmium through fixed-bed column for five cycles. Conditions: inlet cadmium concentration of $5 \mathrm{mg} / \mathrm{L}$, flow rate $5 \mathrm{~mL} / \mathrm{min}$; desorption operation condition: inlet $\mathrm{HCl}$ concentration of $0.1 \mathrm{~mol} \mathrm{dm}^{-3}$, flow rate $50 \mathrm{~mL} / \mathrm{min}$.
Table 9

Column regeneration parameters for GRM-packed column (adsorption operation condition: inlet concentration of $5 \mathrm{mg} / \mathrm{L}$, flow rate $5 \mathrm{~mL} / \mathrm{min}$ )

\begin{tabular}{lc}
\hline First cycle & \\
$q_{\mathrm{acmax}}^{\mathrm{e}}(\mathrm{mg} / \mathrm{g})$ & 5.92 \\
$E_{\mathrm{D}}(\%)$ & 89.0 \\
& \\
Second cycle & \\
$q_{\mathrm{acmax}}^{\mathrm{e}}(\mathrm{mg} / \mathrm{g})$ & 5.23 \\
$E_{\mathrm{D}}(\%)$ & 75.2 \\
& \\
Third cycle & \\
$q_{\mathrm{acmax}}^{\mathrm{e}}(\mathrm{mg} / \mathrm{g})$ & 4.53 \\
$E_{\mathrm{D}}(\%)$ & 62.5 \\
& \\
Fourth cycle & \\
$q_{\mathrm{acmax}}^{\mathrm{e}}(\mathrm{mg} / \mathrm{g})$ & 3.22 \\
$E_{\mathrm{D}}(\%)$ & 35.4 \\
\hline
\end{tabular}

proper quantity have been proven to be very effective for GRMpacked column desorption. As also reflected in the experimental data as Fig. 9, each cycle of the consecutive desorption tests can be completed in 140 min while the recovered GRM column can be utilized for four cycles until completely exhausted. Due to the loss of adsorption capability of GRM column, the regeneration efficiency decreased with the consecutive adsorption cycle accordingly as less cadmium can be desorbed from the GRM-packed column.

\section{Conclusions}

From the research results in this paper, it can be concluded that the granular red mud adsorbent exhibits itself a high capability to adsorb $\mathrm{Cd}$ ions from aqueous solutions. The adsorption on GRM is a spontaneous and feasible process, which confirms an endothermic nature of cadmium adsorption. The experimental adsorption kinetics at initial $\mathrm{pH} 3.0$ and $\mathrm{pH} 6.0$ can be fairly fitted by the pseudo-second-order kinetics model. Particularly, for the mass transfer process in GRM-cadmium system at initial $\mathrm{pH} 6.0$, the processes are mainly intraparticle-diffusion-controlled through the analysis of external mass transfer coefficient and effective particle diffusion coefficients with regards to different initial cadmium concentration of $50 \mathrm{mg} / \mathrm{L}, 100 \mathrm{mg} / \mathrm{L}$ and $200 \mathrm{mg} / \mathrm{L}$. Through the analysis of cadmium adsorption breakthrough curves from GRM-packed columns, "high inlet concentration, low flow rate" have exhibited a better ability to adsorb the same inlet mass flux before exhausted. Thomas model can be used to model column adsorption results. The cadmium-loaded GRM adsorbents can be regenerated four cycles after each cycle of adsorption. The high capability to remove cadmium completely at low concentrations, high adsorption capacity in batch and column adsorption and fine reversibility to be regenerated rapidly for four cycles indicate that granular red mud can be used in heavy metals adsorption as an upgraded product for powdered red mud adsorbents. 


\section{Acknowledgements}

The authors are very thankful to Shandong Aluminum Cop. Ltd., China for their generous support throughout the research work.

\section{Appendix A. Supplementary data}

Supplementary data associated with this article can be found, in the online version, at doi:10.1016/j.seppur.2007.03.013.

\section{References}

[1] S. Hasan, A. Krishnaiah, T.K. Ghosh, D.S. Viswanath, V.M. Boddu, E.D. Smith, Ind. Eng. Chem. Res. 45 (2006) 5066.

[2] S. Manahan, Environmental Chemistry, Lewis Publishers, Florida, 1994.

[3] M. Ulmanu, E. Maronon, Y. Fernandez, L. Castrillon, I. Anger, D. Dumitriu, Water Air Soil Poll. 142 (2003) 357.

[4] S.S. Tripathy, J.-L. Bersillon, K Gopal, Desalination 19 (2006) 11.

[5] W.A. Chun, K.C. Chak, F.P. John, G. Mckay, Environ. Sci. Technol. 35 (2001) 1511.

[6] C. Gabaldón, P. Marzal, F.J. Alvarez-Hornos, J. Chem. Technol. Biotechnol. 81 (2006) 1107-1112.

[7] C. Brunori, C. Cremisini, P. Massanisso, V. Pinto, L. Torricelli, J. Hazard. Mater. B 117 (2005) 55.
[8] R. Apak, K. Güclü, M.H. Turgut, J. Colloid Interf. Sci. 203 (1998) 122.

[9] V.K. Gupta, S. Sharma, Environ. Sci. Technol. 36 (2002) 3612.

[10] I. Voinovitch, J. Debrad-Guedon, J. Louvrier, The Analysis of Silicates, Israel Program for Scientific Translations, Jerusalem, 1966, pp. 127-129.

[11] D. Chvedov, S. Ostap, T. Le, Colloid Surf. A 182 (2001) 131.

[12] H.K. An, B.Y. Park, D.S. Kim, Water Res. 4 (2001) 3551

[13] T. Vaughan, C.W. Seo, W.E. Marshall, Bioresour. Technol. 78 (2001) 133.

[14] S. Al-Asheh, Z. Duvnjak, J. Hazard. Mater. 56 (1997) 35-51.

[15] A. Resat, T. Esma, H. Mehmet, H. Julide, Water Res. 32 (1998) 430-440.

[16] C. Cabrera, C. Gabaldon, P. Marzal, J. Chem. Technol. Biotechnol. 80 (2005) 477.

[17] G. Mckay, M.E. Geundi, M.M. Nassar, Trans. Inst. ChemE. 74 (1996) 277.

[18] S. Dutta, J.K. Basu, R.N. Ghar, Sep. Purif. Technol. 21 (2001) 227.

[19] G.M. Walker, L. Hansen, J.-A. Hanna, S.J. Allen, Water Res. 37 (2003) 2081.

[20] Z. Aksu, İ.A. İşoğlu, Process. Biochem. 40 (2005) 3031.

[21] W.J. Weber, J.C. Morris, J. San, J. Sanit. Eng. Div. Am. Soc. Civ. Eng. 89 (1963) 31.

[22] D. Reichenberg, J. Am. Chem. Soc. 75 (1953) 589.

[23] F. Helfferich, Ion Exchange, McGraw-Hill, New York, 1962.

[24] V.K. Gupta, A. Mittal, V. Gajbe, J. Colloid Interf. Sci. 284 (2005) 89

[25] V.K. Gupta, A. Mittal, L. Krishnan, V. Gajbe, Purif. Technol. 40 (2004) 87.

[26] M.H. Kalavathy, T. Karthikeyan, S. Rajgopal, L.R. Miranda, J. Colloid Interf. Sci. 292 (2005) 354.

[27] H.C. Thomas, Chromatography: a problem in kinetics, Annu. N Y Acad. Sci. 49 (1948) 161.

[28] T.D. Reynolds, P.A. Richards, Unit Operations and Processes in Environmental Engineering, PWS Publishing Company, New York, USA, 1996. 